\title{
Note
}

\section{Use of Camera Traps Provides Insight into the Feeding Ecology of Red Foxes (Vulpes vulpes)}

\author{
CASEy J. WAGNON ${ }^{1}$ and ThOMAS L. SERFASS ${ }^{1,2}$ \\ ${ }^{1}$ Department of Biology, Frostburg State University, 101 Braddock Road, Frostburg, Maryland 21532 USA \\ ${ }^{2}$ Corresponding author: tserfass@frostburg.edu
}

Wagnon, Casey J., and Thomas L. Serfass. 2017. Use of camera traps provides insight into the feeding ecology of Red Foxes (Vulpes vulpes). Canadian Field-Naturalist 131(1): 19-22. https://doi.org/10.22621/cfn.v131i1.1950

Red Foxes (Vulpes vulpes) often carry food items to caching sites and while making provisioning trips to litters. This behaviour provides opportunities to use camera traps to record Red Foxes carrying food that is likely prey. As part of a larger study using camera-trap surveys to monitor carnivore populations at Great Swamp National Wildlife Refuge, New Jersey, our cameras also recorded Red Foxes carrying food items allowing us to gain insight into the feeding ecology of this predator. Camera traps documented Red Foxes carrying food 71 times; items included mammals (78.9\%), birds (19.7\%), and fish (1.4\%). Small mammals (unknown rodent or soricid species [23.9\%] and voles [Microtus or Clethrionomys spp.; 5.6\%]) were the most common groups of food items and Muskrat (Ondatra zibethicus; $15.5 \%$ ) was the most common food item identified to species. Our surveys corroborate traditional diet assessments (e.g., scat analysis) of Red Foxes in North America, identifying them as a generalist forager that typically consumes smaller mammals. We also highlight the potential to apply camera trapping as a supplemental technique for gaining additional insight into the feeding ecology of this predator.

Key Words: Camera trap; diet; prey; Red Fox; Vulpes vulpes; Great Swamp National Wildlife Refuge

Identification of food remains in scats collected in the field and stomachs from carcasses of trapped individuals has been the primary source of dietary information for many species in the order Carnivora (Mills 1996; Klare et al. 2011), including the Red Fox (Vulpes vulpes; Doncaster et al. 1990; Sheldon 1992; Glen and Dickman 2008; Barrull et al. 2014). For example, Hockman and Chapman (1983) examined 128 Red Fox stomachs collected from trapped animals in Maryland during the autumn and winter seasons and concluded that Red Foxes primarily consumed small mammals (i.e., Meadow Voles [Microtus pennsylvanicus] and Eastern Cottontails [Sylvilagus floridanus]). Similarly, Ozoga et al. (1982) concluded that Deer Mice (Peromyscus maniculatus) and Meadow Voles were important food items identified in 367 Red Fox scats from Michigan's Upper Peninsula during the spring and summer. Red Foxes are generalist foragers and, in addition to consuming small mammals, have been reported to consume birds, fruits/seeds, invertebrates, carrion, and fish (Cypher 1982).

Camera-trap surveys are an effective method for investigating carnivore populations (Kays and Slauson 2008; O'Connell et al. 2011; McCallum 2013) and may offer a novel approach to document their feeding ecology. Red Foxes display foraging behaviours that may lend well to them being detected with food items by camera traps. For example, Red Foxes often cache prey instead of consuming it on site (Murie 1936; MacDonald 1976; Dekker 1983; Henry 1986; Lariviere and Pasitschniak-Arts 1996) and, thus, travel from capture to cache sites with prey in the mouth. Also, Red Foxes have been reported to carry food to den sites during the pup-rearing season (Sargeant et al. 1984). Consequent- ly, monitoring likely travel corridors (e.g., natural or human-made pathways) with camera traps may provide opportunities to detect and identify food being carried by Red Foxes (Ballard et al. 2014). As part of a larger study using camera-trap surveys to monitor carnivores occupying Great Swamp National Wildlife Refuge (GSNWR), Morris County, New Jersey $\left(40^{\circ} 42^{\prime} 40.73^{\prime \prime} \mathrm{N}, 74^{\circ} 27^{\prime} 52.82^{\prime \prime} \mathrm{W}\right)$, we identified food items being carried by Red Foxes from our image dataset. Here we provide a description of taxa carried by Red Foxes and highlight the potential for using camera traps to gain insight into the diet of this predator.

From 24 November 2013 to 25 October 2014, 20 camera traps (Cuddeback Attack Flash and Capture Flash, De Pere, Wisconsin, USA) were located at intervals of $250-550 \mathrm{~m}$ to monitor the refuge's $10.5 \mathrm{~km}$ of service roads. Camera traps (in a Cuddeback Bear Safe, De Pere, Wisconsin, USA) were attached to wooden stakes $(150 \mathrm{~cm}$ by $5.08 \mathrm{~cm}$ by $5.08 \mathrm{~cm})$ placed approximately $1.5-2 \mathrm{~m}$ from the edge of the roads and at a height of $0.3-1 \mathrm{~m}$ off the ground. Camera traps were positioned perpendicular to roads and no bait or lure was used during the surveys (see Wagnon 2015 for complete details of methods).

In total, camera traps surveyed roads for 4866 camera trap nights (CTN). Survey effort was greater in summer (June, July, and August; $1581 \mathrm{CTN}$ ) and spring (March, April, and May; 1200 CTN) and less in autumn (September, October, November; 1064 CTN) and winter (December, January, and February; 1021 CTN). Camera traps recorded 2883 independent events involving Red Foxes (i.e., images of a fox at a site separated by $>60 \mathrm{~min}$ ) for an average of 240.3 events/month (range 35 in November 2013 to 528 in August 2014; 
standard deviation 153.8). Among all Red Fox photos ( $n=3986), 71$ were of an individual animal carrying a food item. Red Foxes were photographed with food most frequently during the spring $(n=40)$ and summer $(n=22)$ and less frequently during autumn $(n=1)$ and winter $(n=8)$.

Food items were identified to the finest taxonomic level and the frequency of occurrence was calculated (i.e., number of images with the food item divided by the total number of images with food $[n=71]$ multiplied by 100). Food items represented three general taxonomic categories (i.e., mammal, avian, and fish; Table 1). Most of the food items were mammals (78.9\%), comprising mainly unknown rodent or soricid species (23.9\%), unknown mammals (23.9\%), and Muskrats (Ondatra zibethicus, 15.5\%; Figure 1, Table 1). However, Red Foxes were also recorded twice with a juvenile Raccoon (Procyon lotor; Figure 1), presumably examples of intraguild predation (Polis et al. 1989). Examples of Red Foxes carrying avian food items (birds $11.2 \%$ and eggs $8.5 \%$ ) and a Largemouth Bass (Micropterus salmoides, 1.4\%) were also represented in images (Table 1, Figure 1).

Similar to Red Fox scat/stomach analyses in North America, our image dataset indicates that Red Foxes are generalist foragers and frequently feed on mammals. During autumn, fruit/seeds may constitute $100 \%$ of their diet (Cypher 1982) and would not have been detected in our camera-trap images. Shifts in diet to fruits/seeds may explain the few events of foxes with food during autumn $(n=1)$, even though 730 events were recorded for that period. Moreover, adults would no longer be engaged in provisioning trips after pups disperse in late summer and early autumn, likely reducing the chances of detecting Red Foxes with food. These examples demonstrate the limitations of camera traps in allowing comprehensive diet assessments for Red Foxes (and other wildlife). However, camera-trap surveys could complement traditional diet analyses (i.e., food identified in scats or stomachs) and provide additional details on the feeding ecology of Red Foxes. For example, egg predation would likely be missed or underestimated in traditional diet analyses, because foxes may only consume the nutrient-rich embryo and not the eggshell (i.e., the only evidence of egg predation discernible in scats or stomachs). Also, camera traps could provide useful insight into Red Fox consumption of species of management (e.g., rare, game, or invasive species) or economic interest (e.g., livestock). Our camera-trapping effort documented five incidents of Red Foxes with waterfowl, a group recognized as a management priority at GSNWR (United States Fish and Wildlife Service 2014). Further, our image dataset provided evidence of a potential ecological service carried out by Red Foxes; we documented three incidents of Red Foxes carrying a non-native rat (Rattus rattus or $R$. norvegicus), which are invasive species of considerable ecological concern (Maggs et al. 2015).

Examining the feeding ecology of Red Foxes was not the primary purpose of our study, but our cameratrap survey provided an opportunity to gain insight into Red Fox foraging habits through the unexpected collection of ancillary information. Our analysis under-

TABLE 1. The number and frequency of occurrence of food items carried by Red Foxes (Vulpes vulpes), and the total number of prey-carrying events recorded during camera-trap surveys at Great Swamp National Wildlife Refuge, New Jersey, from 24 November 2013 to 25 October 2014. Camera traps recorded 730, 296, 631, and 1226 independent events of Red Fox in the fall, winter, spring, and summer, respectively.

\begin{tabular}{|c|c|c|c|c|c|c|}
\hline \multirow[b]{2}{*}{ Food item } & \multicolumn{5}{|c|}{ No. of records } & \multirow[b]{2}{*}{$\%$} \\
\hline & $\begin{array}{c}\text { Fall } \\
(n=1)\end{array}$ & $\begin{array}{l}\text { Winter } \\
(n=8)\end{array}$ & $\begin{array}{c}\text { Spring } \\
(n=40)\end{array}$ & $\begin{array}{l}\text { Summer } \\
(n=22)\end{array}$ & $\begin{array}{c}\text { Total } \\
(n=71)\end{array}$ & \\
\hline \multicolumn{7}{|l|}{ Mammals } \\
\hline Unknown Rodentia or Soricididae & 1 & 0 & 10 & 6 & 17 & 23.9 \\
\hline Unknown mammal & 0 & 0 & 10 & 7 & 17 & 23.9 \\
\hline Muskrat (Ondatra zibethicus) & 0 & 4 & 6 & 1 & 11 & 15.5 \\
\hline Vole (Microtus or Clethrionomys spp.) & 0 & 0 & 4 & 0 & 4 & 5.6 \\
\hline Black or Brown Rat (Rattus rattus or R. norvegicus) & 0 & 1 & 1 & 1 & 3 & 4.2 \\
\hline Eastern Cottontail (Sylvilagus floridanus) & 0 & 1 & 1 & 0 & 2 & 2.8 \\
\hline Raccoon (Procyon lotor) & 0 & 0 & 0 & 2 & 2 & 2.8 \\
\hline Total & 1 & 6 & 32 & 17 & 56 & 78.9 \\
\hline \multicolumn{7}{|l|}{ Avian species } \\
\hline Avian egg & 0 & 0 & 6 & 0 & 6 & 8.5 \\
\hline Mallard (Anas platyrhynchos) & 0 & 1 & 1 & 1 & 3 & 4.2 \\
\hline Unknown waterfowl & 0 & 0 & 0 & 2 & 2 & 2.8 \\
\hline Wild Turkey (Meleagris gallopavo) poult & 0 & 0 & 0 & 1 & 1 & 1.4 \\
\hline Rail (Rallus sp.) & 0 & 1 & 0 & 0 & 1 & 1.4 \\
\hline Unknown bird & 0 & 0 & 0 & 1 & 1 & 1.4 \\
\hline Total & 0 & 2 & 7 & 5 & 14 & 19.7 \\
\hline \multicolumn{7}{|l|}{ Fish } \\
\hline Largemouth Bass (Micropterus salmoides) & 0 & 0 & 1 & 0 & 1 & 1.4 \\
\hline
\end{tabular}




\section{A}

B

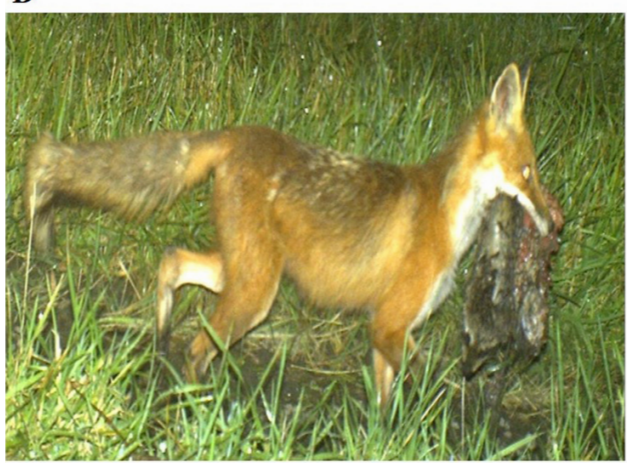

D

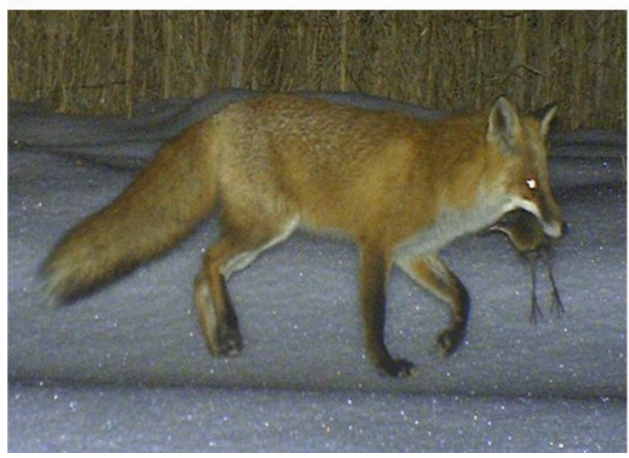

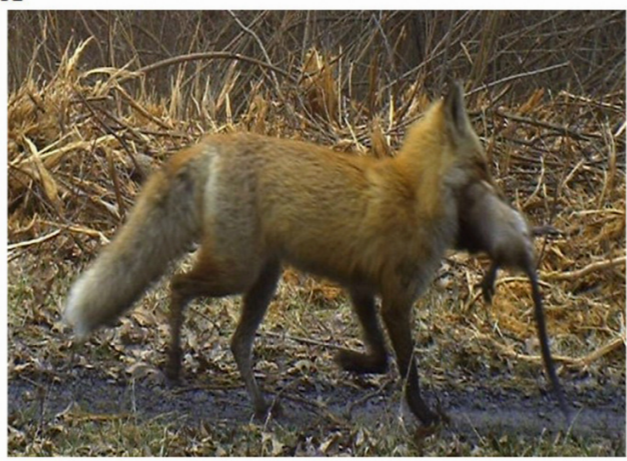

C

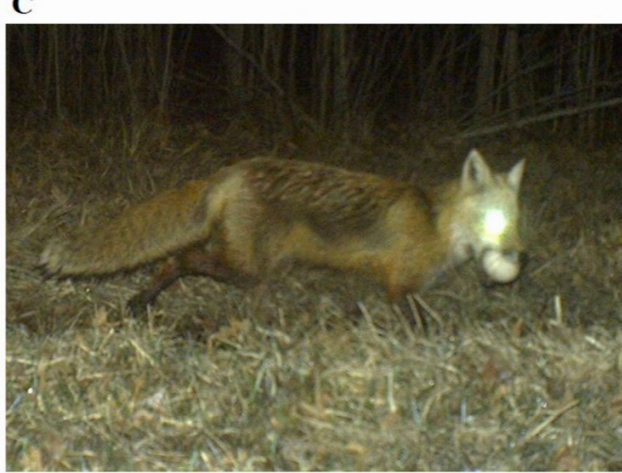

E

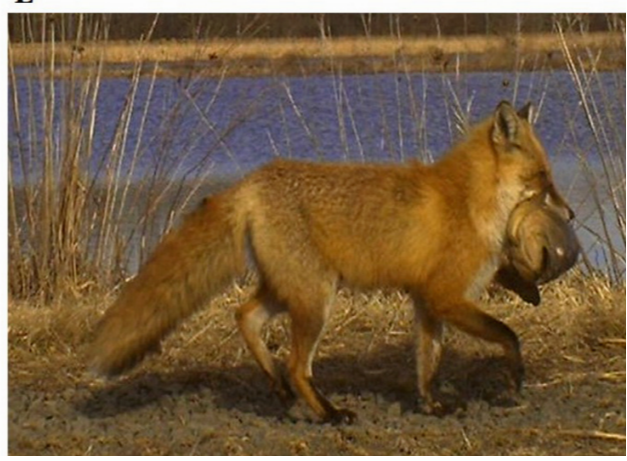

FIGURE 1. Images of Red Foxes (Vulpes vulpes) carrying food items recorded during camera-trap surveys at Great Swamp National Wildlife Refuge, Morris County, New Jersey, from 24 November 2013 to 25 October 2014. Prey items are (A) Muskrat (Ondatra zibethicus), (B) juvenile Raccoon (Procyon lotor), (C) avian egg, (D) Rail (Rallus sp.), and (E) Largemouth Bass (Micropterus salmoides). Photos: C. Wagnon.

scores the value of camera traps in collecting data that may address interesting questions and natural history observations not directly related to the scope of a study.

\section{Acknowledgements}

This study received financial support from the Friends of Great Swamp National Wildlife Refuge, Basking Ridge, New Jersey, USA (Frostburg State University project 5159005). We thank this exceedingly generous group. We also thank the following United States Fish and Wildlife Service staff at GSNWR for facilitating many logistical aspects of our study: D. M. Wells, D. Sagan, S. Henry, D. Miller, M. McMenamin, and J. Pimental. We thank Frostburg State University for providing logistic support and the two anonymous reviewers for greatly improving the manuscript.

\section{Literature Cited}

Ballard, G., P. D. Meek, S. Doak, P. J. S. Fleming, and J. Sparkes. 2014 Camera traps, sand plots and known events: what do camera traps miss? Pages 189-202 in Camera Trapping: Wildlife Management and Research. Edited by 
P. D. Meek and P. J. S. Fleming. CSIRO Publishing, Collingwood, Victoria, Australia.

Barrull, J., I. Mate, J. Ruiz-Olmo, J. G. Casanovas, J. Gosãlbez, and M. Salicrú. 2014. Factors and mechanisms that explain coexistence in a Mediterranean carnivore assemblage: an integrated study based on camera trapping and diet. Mammalian Biology 79: 123-131. https://doi.org /10.1016/j.mambio.2013.11.004

Cypher, B. L. 1982. Foxes. Pages 511-546 in Wild Mammals of North America: Biology, Management, and Conservation. Edited by G. A. Feldhamer, B. C. Thompson, and J. A. Chapman. Second edition. Thompson Johns Hopkins, Baltimore, Maryland, USA.

Dekker, D. 1983. Denning and foraging habits of red fox, Vulpes vulpes, and their interactions with coyotes, Canis latrans, in Central Alberta, 1972-1981. Canadian FieldNaturalist 97: 303-306.

Doncaster, C. P., C. R. Dickman, and D. W. Macdonald. 1990. Feeding ecology of red foxes (Vulpes vulpes) in the city of Oxford, England. Journal of Mammalogy 71: 188194. https://doi.org/10.2307/1382166

Glen, A. S., and C. R. Dickman. 2008. Niche overlap between marsupial and eutherian carnivores: does competition threaten the endangered Spotted-tailed Quoll? Journal of Applied Ecology 45: 700-707. https://doi.org/10 $.1111 /$ j.1365-2664.2007.01449.x

Henry, J. D. 1986. Red Fox: The Catlike Canine. Smithsonian Institution Press, Washington, DC, USA.

Hockman, J. G., and J. A. Chapman. 1983. Comparative feeding habits of red foxes (Vulpes vulpes) and gray foxes (Urocyon cinereoargenteus) in Maryland. American Midland Naturalist 110: 276-285. https://doi.org/10.2307/242 5269

Kays, R.W., and Slauson, K. M. 2008. Remote cameras. Pages 111-140 in Noninvasive Survey Methods for Carnivores. Edited by R. A. Long, P. MacKay, W. J. Zielinski, and J. C. Ray. Island Press, Washington, DC, USA.

Klare, U., J. F. Kamler, and D. W. Macdonald. 2011. A comparison and critique of different scat-analysis methods for determining carnivore diet. Mammal Review 41: 294 312. https://doi.org/10.1111/j.1365-2907.2011.00183.x

Lariviere, S., and M. Pasitschniak-Arts. 1996. Vulpes vulpes. Mammalian Species 537: 1-11.

Macdonald, D. W. 1976. Food caching by red foxes and some other carnivores. Journal of Comparative Ethology 42: $170-185$.

Maggs, G., M. Nicoll, N. Zuëlc, P. J. C. Whited, E. Winfield, S. Poongavananc, V. Tatayahc, C. Jones, and K. Norrisa. 2015. Rattus management is essential for popu- lation persistence in a critically endangered passerine: combining small-scale field experiments and population modelling. Biological Conservation 191: 274-281. https://doi .org/10.1016/j.biocon.2015.06.039

McCallum, J. 2013. Changing use of camera traps in mammalian field research: habitats, taxa and study types. Mammal Review 43: 196-206. https://doi.org/10.1111/j.13652907.2012.00216.x

Mills, M. G. L. 1996. Methodological advances in capture, census, and food-habits studies of large African carnivores. Pages 223-242 in Carnivore Behavior, Ecology, and Evolution. Edited by J. L. Gittleman. Second volume. Cornell University Press, Ithaca, New York, USA.

Murie, A. 1936. Following fox trails. Miscellaneous publication 32. University of Michigan Press, Ann Arbor, Michigan, USA.

O'Connell, A. F., J. D. Nichols, and K. U. Karanth. 2011. Camera Traps in Animal Ecology: Methods and Analyses. Springer, New York, New York, USA.

Ozoga, J. J., S. B. Craig, and L. J. Verme. 1982. Red fox feeding habits in relation to fawn mortality. Journal of Wildlife Management 46: 242-243. https://doi.org/10.2307 /3808428

Polis, G. A., C. A. Myers, and R. D. Holt. 1989. The ecology and evolution of intra-guild predation: potential competitors that eat each other. Annual Review of Ecology and Systematics 20: 297-330. https://doi.org/10.1146/annurev .es.20.110189.001501

Sargeant, A. B., S. H. Allen, and R. T. Eberhardt. 1984. Red fox predation on breeding ducks in Midcontinent North America. Wildlife monograph 89. Wildlife Society, Bethesda, Maryland, USA.

Sheldon, J. W. 1992. Genus Vulpes. Pages 162-203 in Wild Dogs. Edited by J. W. Sheldon. Academic Press, San Diego, California, USA, and London, United Kingdom.

United States Fish and Wildlife Service. 2014. Great Swamp National Wildlife Refuge comprehensive conservation plan. United States Department of Interior, Fish and Wildlife Service. Great Swamp National Wildlife Refuge, Basking, Ridge, New Jersey, USA.

Wagnon, C. 2015. Surveying for carnivores with camera traps: an evaluation of carnivore detection patterns at Great Swamp NWR and the implications for camera-trap survey design. M.Sc. thesis, Frostburg State University, Frostburg, Maryland, USA.

Received 1 June 2016

Accepted 25 February 2017 